\title{
El límite económico al cumplimiento de contrato. Desde la excesiva onerosidad sobrevenida a los costos excesivos del cumplimiento específico
}

\section{Economic Limits to Contractual Performance: From Hardship to the Unreasonable Costs of Specific Performance}

Rodrigo Momberg-Uribe

Pontificia Universidad Católica de Valparaiso, Chile

rodrigo.momberg@pucv.cl

ORCID: http://orcid.org/0000-0002-4774-4256

Álvaro Vidal-Olivares

Pontificia Universidad Católica de Valparaiso, Chile

ORCID: http://orcid.org/0000-0001-5362-9310
DOI: https://doi.org/10.11144/Javeriana.vj137.lecc Redalyc: http://www.redalyc.org/articulo.oa?id=82556549008

\section{Resumen:}

El presente trabajo se propone analizar el estado dogmático del límite económico a la pretensión de cumplimiento del contrato, y la imprevisión o excesiva onerosidad sobrevenida, para considerar las condiciones, ámbitos de aplicación y efectos de ambas figuras en el derecho de contratos, con el objetivo de delinear los campos operativos de cada instituto y despejar las confusiones existentes sobre el particular.

Palabras clave: Cumplimiento específico, imprevisión, límite a la pretensión de cumplimiento, derecho uniforme.

\section{Abstract:}

The paper analyses two devices, the unreasonable burden or costs as limit to specific performance, and hardship or change of circumstances, examining their conditions, scope of application and effects, with the aim of outlining their operative fields, solving the current confusions on the subject.

Keywords: Specific performance, hardship, unreasonable burden, uniform law.

\section{El problema}

El derecho de contratos reconoce al acreedor afectado por el incumplimiento, entre otros remedios, la pretensión de cumplimiento específico que se traduce en el derecho del acreedor a exigir al deudor la ejecución de lo pactado conforme con el contrato. El nuevo derecho de contratos ha ubicado este derecho en el lugar que le es propio - el sustantivo-y lo ha apartado de lo procesal que refiere al procedimiento de la ejecución forzosa de una sentencia que, precisamente, condena al deudor a cumplir. Fuera de situarse en el plano sustantivo, esta pretensión deja de ser considerada un remedio primario respecto de la indemnización de daños compensatoria y que se da en lugar de la prestación, y lo sitúa en un plano de horizontalidad, ya no solo con la resolución, sino también con la pretensión resarcitoria, lo cual lleva a afirmar que el acreedor puede elegir u optar por ejercitar cualquiera de los tres remedios ${ }^{1}$, sin otros límites que sus condiciones de procedencia y aquellos que imponga la ley o provengan de la buena fe objetiva ${ }^{2}$ o la doctrina del abuso del derecho ${ }^{3}$.

Como se quiera, en la tradición del derecho civil o continental, el acreedor es titular del derecho a hacer cumplir específicamente lo pactado, haciendo efectivo el principio de la fuerza obligatoria del contrato ${ }^{4}$. En principio, si el acreedor demanda el cumplimiento, concurriendo sus condiciones de procedencia —su supuesto-, el juez debe reconocer al acreedor el derecho y condenar al deudor. Empero, hemos de considerar que si bien el acreedor tiene derecho al cumplimiento, los instrumentos de derecho uniforme y armonizado de derecho de contratos reconocen límites a su ejercicio y en nuestro derecho civil, pese a no haber norma expresa que así lo establezca, se concluye lo mismo: el acreedor está sometido a límites en el ejercicio de su pretensión de cumplimiento que se extraen del principio o cláusula general de la buena fe objetiva del artículo 
1546 del Código Civil ${ }^{5}$. Si coincidimos en lo expresado, debemos prestar atención al supuesto y a los límites al ejercicio de este derecho, en especial, aquel de carácter económico.

Cuando hablamos del supuesto de la pretensión, estamos dando respuesta a la siguiente interrogante: ¿̇tiene el acreedor, en el caso concreto, derecho a exigir el cumplimiento? En cambio, cuando la interrogante refiere a los límites, no está en discusión el derecho del acreedor a hacer cumplir lo pactado, sino su ejercicio en tal caso. En otros términos, la pregunta es épuede el acreedor, ante la infracción contractual de su deudor, ejercitar su derecho, exigiéndole la realización de lo pactado? Es precisamente la separación entre titularidad del derecho y su ejercicio la que nos permite definir el objeto de este trabajo y, al mismo tiempo, justificarlo.

El régimen de la pretensión de cumplimiento específico se ha construido desde estas dos veredas - sus condiciones de procedencia y los límites a su ejercicio-, que al relacionarlas provocan una cierta confusión, turbando su correcta comprensión como remedio del acreedor y de su relación con el cumplimiento y el incumplimiento.

Y esta confusión se produce entre el costo excesivo que impone al deudor la corrección de su incumplimiento - realización específica del interés del acreedor- y la excesiva onerosidad sobrevenida del cumplimiento como excusa del mismo. Tanto el primero, como la segunda son defensas del deudor para escapar de la ejecución de su prestación tal cual fue pactada y, en ambas hipótesis, el deudor, apoyándose en una razón de orden económico, se niega a cumplir, sea porque sobreviene la excesiva onerosidad de la ejecución de la prestación, sea porque, ya producido el incumplimiento, se niega a ejecutarla, esta vez porque la pretensión de cumplimiento específico - del acreedor - le impone costos desproporcionados. Nos situamos en el entorno de los límites económicos al cumplimiento del contrato y el desafío está, precisamente, en delimitar el lugar que le cabe a cada uno de ellos, es decir, fijar cuál es el ámbito de aplicabilidad de la excesiva onerosidad y aquel del coste desproporcionado de la ejecución específica.

Esta confusión se advierte con bastante nitidez en los Comentarios Oficiales al artículo 7.2.2.b de los Principios sobre Contratos Comerciales Internacionales del Instituto Internacional para la Unificación del Derecho Privado, Unidroit (PCCI) ${ }^{6}$ y, también, en los juristas que han estudiado la disposición.

El artículo citado prevé, entre las excepciones al derecho al cumplimiento específico de las obligaciones no dinerarias, aquella referida a casos en los que "la prestación, o en su caso, la ejecución forzosa sea excesivamente gravosa u onerosa”. De la letra de la norma se aprecia que ella confunde este límite al cumplimiento con el de la imprevisión o hardship que los mismos Principios disciplinan en su artículo 6.2.2. Y no solo eso, sino que en los comentarios de la primera disposición leemos que:

En casos excepcionales, particularmente cuando hubo un cambio drástico de las circunstancias después de la celebración del contrato, el cumplimiento podría ser todavía posible, pero tan oneroso que reclamarlo en forma específica atentaría contra el principio general de buena fe y lealtad negocial (véase el artículo 1.7) ${ }^{7}$.

Del párrafo transcrito es evidente que los comentarios incurren en un error al confundir dos reglas diversas, al punto de que aquella sobre límite económico a la pretensión de cumplimiento específico pierde su fisonomía al ser absorbida por la imprevisión o hardship. Entonces ecuál es la línea divisoria entre la regla que limita el ejercicio del remedio y aquella que justifica el incumplimiento? Esta tarea se hace más difícil si prestamos atención al ejemplo que dan los comentarios para ilustrarnos sobre la disposición, al expresar:

1. Un buque petrolero naufraga en aguas costeras durante una fuerte tempestad. Aunque sería posible recuperar el buque del fondo del mar, el cargador no podría reclamar el cumplimiento del contrato de transporte si esto fuese a ocasionar al naviero gastos muy por encima del valor del petróleo (véase el artículo 7.2.2.b) ${ }^{8}$.

El ejemplo está formulado a partir del caso del anillo que se pierde en el fondo de un lago y al que usualmente recurre la doctrina alemana para explicar la denominada "imposibilidad práctica" (faktische Unmöglichkeit), que actúa como límite a la pretensión de cumplimiento específico conforme lo dispone el \$275II del BGB ${ }^{9}$. Ahora bien, un caso como el descrito podría, en otros sistemas de derecho civil y, en particular, en aquellos de 
influencia francesa, calificarse como una hipótesis de caso fortuito que excusa al deudor de cumplir y que más que limitar el derecho del acreedor al exigir el cumplimiento específico, extinguiría la obligación del deudor al tratarse de un obstáculo, en sí y en sus consecuencias, definitivamente insuperable o irresistible — en el caso chileno-, de acuerdo al artículo 45 de nuestro Código Civil ${ }^{10}$.

Como anticipamos, quienes comentan las reglas concernidas de los PCCI, incurren en la misma imprecisión de conceptos al diferenciar la imprevisión, del límite económico del cumplimiento especifico. Así, al pronunciarse sobre el citado art. 7.2.2.b, HARRIET SCHELHAAS afirma que la distinción -la del límite económico - con los casos de hardship es bien "delicada y, añade que, estos conceptos usualmente se superponen" 11 , llegando al extremo de afirmar que unos mismos hechos podrán configurar una u otra hipótesis y sugiere que, si es el caso, la parte afectada tendría la opción de elegir entre los dos medios de defensa 12 .

De los comentarios a esta disposición de los PCCI, una correcta comprensión de la exigibilidad de lo pactado y del derecho del acreedor a exigir la realización del contrato en caso de incumplimiento, justifica los esfuerzos por dilucidar la tenue, pero dogmáticamente marcada, frontera entre la imprevisión o excesiva onerosidad sobrevenida y el límite económico de la pretensión de cumplimiento específico. He ahí el origen y justificación de las ideas que queremos compartir con ustedes.

Para alcanzar este propósito, ante todo hemos de coincidir en que las dos reglas en cuestión constituyen un límite a la vigencia del principio de la fuerza obligatoria del contrato del art. 1545 del Código Civil; sin embargo, no cabe confundirlas, pues cada una posee sus propios contornos que le confieren su fisonomía y ámbito de aplicación. Y estas definiciones no solo interesan a la dogmática del derecho civil, sino también a los contratantes y operadores que conocen y resuelven conflictos en torno al cumplimiento e incumplimiento del contrato (jueces y árbitros). Quiere decir, entonces, que la solución a la que arribemos tiene un interés dogmático que repercute directamente en la práctica contractual.

La pregunta que hemos de formularnos es ¿por qué se confunden dos reglas diversas? La respuesta es que, aparentemente, estaríamos hablando de lo mismo; a saber, de un cumplimiento que resulta excesivamente costoso para el deudor. Sin embargo, mirar las cosas de manera tan sencilla es una trampa que nos puede hacer tropezar y caer abruptamente. Si así sucede, solo podremos ponernos de pie si tomamos en serio estas dos reglas diversas y profundizamos sobre su noción, justificación y los efectos que le son propios.

Para alcanzar este objetivo, en un primer momento, presentaremos dos casos, cuyo análisis contribuirá a una mejor comprensión del problema planteado, casos a los que recurriremos en la medida en que avancemos en su desarrollo con miras a su solución. Enseguida, nos referiremos al límite de costo excesivo de la pretensión de cumplimiento específico, con énfasis en su explicación y justificación, incluyendo el análisis de sus efectos; y, luego, a la imprevisión, su justificación y efectos, todo con la única finalidad de demarcar el ámbito de esta última de aquel del primero. El trabajo termina con unas breves conclusiones.

\section{Dos casos}

Para una mejor comprensión del problema planteado, pensemos en dos casos en los que el costo de ejecución de lo pactado representa un límite a su cumplimiento.

1

La empresa A, en adelante "el mandante", encarga a la empresa B, en adelante "la constructora", la construcción de una vivienda. En el contrato, las partes definen en detalle las especificaciones técnicas para la ejecución de la prestación. De acuerdo a estas, la constructora debía importar desde Estados Unidos de Norteamérica casi un $60 \%$ de los materiales y artefactos para la realización de la obra. Las partes están de acuerdo en el precio, en su forma de pago y en el plazo para la ejecución de la prestación. Una vez celebrado 
el contrato, aún pendiente su ejecución, la salida del Reino Unido de la Unión Europea produjo un fuerte impacto en el dólar cuyo precio, en moneda local, se elevó ostensiblemente. A lo anterior se suma que el nuevo Presidente de Estados Unidos desahució el tratado de libre comercio con el Estado en el que se ejecutarían las obras. Estas dos circunstancias sobrevenidas provocaron que el costo general de la construcción de la vivienda aumentara en una suma equivalente al $75 \%$ de los costos previstos al momento de contratar y fijar el precio. Debido a lo anterior, la constructora paralizó la ejecución de las obras y se negó a cumplir el contrato.

Si nos detenemos en el caso planteado surgen, al menos, dos interrogantes: ¿̨resulta posible la ejecución del contrato habida cuenta el aumento de costes? La respuesta es evidente, claramente lo es; y si asumimos esta respuesta como correcta, surge otra: ¿es razonable que el mandante - acreedor- exija el cumplimiento del contrato en esas nuevas condiciones económicas y obligue a la constructora a proseguir con las obras?

Nuestra intuición es que no, sin embargo, la pregunta gravitante es ¿ por qué no? Volveremos sobre el punto.

\section{2}

Pensemos en el mismo contrato, pero en uno en el que durante su ejecución no sobreviene ninguna de las circunstancias descritas en el caso anterior. La economía del contrato, salvo algunas variaciones, previsibles al tiempo de su celebración, no se ve sustancialmente alterada. Sin embargo, al concluir el constructor la ejecución de las obras, el mandante — al realizar su inspección final- descubre que las cañerías instaladas no son conformes a las especificaciones técnicas convenidas, al ser de una marca distinta a la designada y acordada y de un costo inferior, sin embargo, de calidad adecuada para su uso en una vivienda cuya construcción se contrató. El mandante, inmediatamente, rechaza la obra, comunica al constructor la infracción contractual y le exige, según lo previsto en el propio contrato, el reemplazo del material no conforme por otro que sí cumpla las especificaciones técnicas convenidas.

$\mathrm{Al}$ igual que en el caso anterior, hemos de plantear dos preguntas: ¿ hay infracción contractual de parte de la constructora?; y, seguidamente, de ser afirmativa la respuesta ¿es posible su corrección? La respuesta a ambas preguntas es bastante obvia. Es claro que la constructora incumple las especificaciones técnicas, no realiza la prestación bajo todos los respectos conforme a lo pactado (art. 1569 Código Civil); y, seguidamente, sí es posible corregir tal incumplimiento.

Ante la respuesta afirmativa a las interrogantes planteadas, surge una tercera cuestión: ¿es razonable, conforme con la buena fe objetiva y el propio interés contractual, que el acreedor exija tal corrección, obligando al deudor a ella? Esta es la pregunta que justifica el trabajo, dado que su respuesta nos permitirá delinear la frontera entre las dos reglas arriba explicadas, el costo excesivo del cumplimiento específico y la imprevisión.

El acreedor pretende hacer cumplir el contrato en los términos estipulados, pretensión que, desde una concepción tradicional de contrato regido por el principio de la fuerza obligatoria, es correcta y no admite discusión alguna. En el primero, el acreedor reclama que se ejecute la obra al precio estipulado; en el segundo, en cambio, que se corrija la anomalía material de la obra y se cumplan las especificaciones técnicas convenidas, sin considerar los mayores costes. De lo hasta aquí expresado, coincidiremos en dos puntos gravitantes para el análisis objeto de este trabajo: a) que en ambos casos, el deudor objetivamente no cumple el contrato -o el deudor deja de cumplir-, o cumple imperfectamente; y b) que tanto la ejecución del contrato, como su corrección son material y jurídicamente posibles. En efecto, pese a la paralización de la obra, de una parte, la constructora sí puede proseguir su ejecución y, de otra, ella también puede corregir la falta de conformidad — sustituyendo las cañerías instaladas por aquellas pactadas-. Sin embargo, en ambas situaciones, el cumplimiento de lo pactado - inicial o corrección - implicaría para el deudor unos costos excesivos y desproporcionados.

Entonces, debemos reflexionar sobre si, en hipótesis como las presentadas, la actual y moderna disciplina del contrato autoriza alejarnos de la concepción tradicional de la fuerza obligatoria - los contratos se celebran 
para cumplirse- y, de este modo, apreciar el problema y resolverlo alejándonos de la idea de la estricta ejecución de lo pactado (el contrato). No divisamos buenas razones para negarlo, sí para aceptarlo; y de estar en lo correcto, quiere decir que la solución se construye no solo desde el citado principio de la fuerza obligatoria, sino también considerando las exigencias y límites que impone la buena fe del artículo 1546 del Código Civil. Por esta razón, hemos de precisar si resulta acorde con las exigencias que impone este último principio exigir al deudor un cumplimiento en términos excesivamente gravosos.

Una adecuada aproximación al problema y a su solución exige distinguir claramente los dos supuestos en cuestión. En el primero, el excesivo coste refiere a la ejecución de la prestación en los términos que originariamente fue convenida: la construcción de una vivienda de acuerdo con el contrato. Aquí, el incremento imprevisto de los costos de ejecución contractual opera como una genuina excusa del cumplimiento, expresada como sigue: no resulta exigible al deudor cumplir en tales términos aun cuando haya consentido en hacerlo, obligándose. La grave, extraordinaria y sobrevenida alteración económica es la que justifica paralizar las obras. En cambio, en el segundo, la constructora ejecuta el contrato - cumple-, con todo, lo hace imperfectamente según lo prescrito por el artículo 1569 CC; y ante la infracción contractual, el acreedor, que tiene la opción entre diversos remedios, exige al deudor corrección de la ejecución no conforme (cumplimiento específico); corrección que, no obstante tener derecho a ella, impone un costo excesivo, el que - como se ha explicado - no concierne a la realización de la prestación originaria - la ejecución de la obra - , sino a la actividad que envuelve la reparación de la obra no conforme con el contrato.

En esta labor de distinguir ambos supuestos, creemos que primero debemos ordenarlas de forma temporal y, al hacerlo, apreciaremos claramente que:

a) El problema de la excesiva onerosidad sobrevenida -imprevisión - se sitúa en el plano del cumplimiento, al comportarse, al mismo tiempo, como causa y excusa del incumplimiento, siendo forzoso definir la posición del acreedor —el mandante- y la del deudor — la constructora-, respecto del cumplimiento conforme a lo pactado y al derecho a exigirlo.

b) En cambio, el de los costos excesivos del cumplimiento específico, el debate no concierne ni a la causa del incumplimiento ni podemos hablar de una excusa del mismo. Nada más alejado de aquello. La obligación le era exigible al deudor en los términos pactados; sin embargo, la realizó desviándose del objeto ideal, de lo convenido. El constructor cumplió, pero lo hizo imperfectamente y hemos de definir si a pesar de que el acreedor detenta el derecho al cumplimiento específico —al ser jurídica y materialmente posible-, está o no autorizado a requerirlo.

\section{Los costos excesivos y la imprevisión contractual: dos límites diversos al cumplimiento}

Hasta aquí podemos anotar que cuando aludimos a la imprevisión y a los costos excesivos, nos referimos a dos reglas que, si bien están conectadas con el cumplimiento del contrato y, en definitiva, con la vigencia que le atribuyamos a la fuerza obligatoria (art. 1545 CC), ciertamente difieren al poseer cada una sus propias condiciones de procedencia, funciones y efectos y, lo más relevante, el momento en que estos se activan: la primera, antes del cumplimiento; y la segunda, después del incumplimiento.

En lo que sigue, tal como lo anticipamos en la primera sección, precisaremos los aspectos distintivos de cada una de estas reglas, recurriendo - cuando sea necesario- a los casos planteados para ilustrar nuestros asertos y mostrar, disipando todo riesgo de confusión, que los costos excesivos representan un límite a la pretensión de cumplimiento específico y que difiere de la imprevisión, al responder cada una a fundamentos y supuestos de hecho y efectos diversos. Así lo hemos venido reiterando desde el principio. Veamos.

Ante todo, hemos de puntualizar que este trabajo no persigue una mera comparación de ambas reglas que es lo típico de la dogmática más tradicional del derecho civil—; su finalidad es aportar a la dogmática, 
para dar claridad a los operadores del tráfico, evitando que el deudor, amparándose en la defensa del costo excesivo del cumplimiento específico, intente encubrir una alegación de imprevisión, burlando, de esta forma, las estrictas exigencias a que ella está sometida.

\section{A. Los costos excesivos del cumplimiento específico}

En primer lugar, nos detendremos en la explicación del límite económico y sus peculiaridades. A pesar de que nuestro derecho privado, a diferencia - como diremos - del derecho uniforme y europeo, no lo establece expresamente, es posible construirlo desde el principio de la buena fe objetiva actuando su función delimitadora del ejercicio de los derechos y facultades dimanados del contrato, en este caso, en la fase del incumplimiento ${ }^{13}$. Los deberes que emanan de este principio se lesionarían gravemente si el acreedor insiste en imponer al deudor un sacrificio económico excesivo, con la excusa de estar haciendo cumplir lo pactado, la ley del contrato ${ }^{14}$.

Este límite se inserta en lo que se ha denominado "la razonable gestión de los efectos del incumplimiento" 15 ; y deja al descubierto la permanente tensión entre fuerza obligatoria - la ley del contrato- y buena fe objetiva, pudiendo sostenerse que, cuando los costes excesivos ponen atajo al derecho al cumplimiento específico, el principio de la buena fe se ha impuesto sobre la fuerza obligatoria. No así en la situación inversa.

$\mathrm{Al}$ referirnos a este límite, asumimos que concurren sus condiciones, en particular, que la ejecución del contrato es material y jurídicamente posible; sin embargo, su ejercicio no procede, en atención al excesivo coste que la ejecución de lo pactado impone al deudor. Ante esta afirmación, primeramente, debemos resolver si al discernir sobre la aplicación de este límite solo hemos de atender al costo excesivo del cumplimiento o, también, a la posibilidad de satisfacción del interés del acreedor. La respuesta a esta interrogante es crucial para delinear correctamente la frontera entre el límite en análisis y la figura de la imprevisión.

Una mirada al derecho uniforme y europeo de contratos - incluidos la reciente reforma francesa y los proyectos españoles - permite constatar que todos los instrumentos, junto con reconocer al acreedor la pretensión de cumplimiento de las obligaciones no dinerarias, someten su ejercicio a un límite de carácter económico. Empero, no hay coincidencia en el modelo que adoptan, así lo denota su propia formulación. En efecto, la Convención de Viena sobre Compraventa Internacional de Mercaderías (CISG), los Principios Unidroit sobre Contratos Comerciales Internacionales (PICC), los Principios Europeos de Derecho de los Contratos (Principles of European Contract Law, PECL), el Borrador de Marco Común de Referencia (Draft Common Frame of Reference, DCFR), la Propuesta de Reglamento de Normativa Común de Compraventa Europea (Common European Sales Law, CESL), la reforma francesa y los proyectos españoles incorporan este límite en términos diversos y con un alcance no necesariamente idéntico, pudiendo agruparse como sigue ${ }^{16}$ :

i. En la CISG, la procedencia de la pretensión de cumplimiento específico está condicionada a que sea razonable atendidas las circunstancias (artículo 46 CISG), entendiéndose que no lo es cuando imponga costes excesivos al deudor ${ }^{17}$.

ii. En el artículo 7.2.2. letra b, de los PCCI ${ }^{18}$; el artículo 9:102, letra b) de los PECL ${ }^{19}$; el III. 3:302, (3), b) del MCR ${ }^{20}$, el nuevo artículo 1121 del Code Civil ${ }^{21}$, el artículo 1192, (2), $2^{\circ}$ de la Propuesta española ${ }^{22}$ y el artículo 518-6, letra b) de la Propuesta de Código Civil español ${ }^{23}$, la pretensión de cumplimiento en esta clase de obligaciones procede en la medida en que no imponga al deudor esfuerzos o gastos no razonables.

iii. El artículo 7.2.2. letra c) de los PICC ${ }^{24}$; y el artículo 9:102(2), letra d), de los PECL ${ }^{25}$, prevén que este remedio no procederá cuando el acreedor pueda razonablemente obtener el cumplimiento por otra vía, es decir, resolviendo el contrato y celebrando una operación de reemplazo. 
iv. Según el III. 3:302 (5) del DCFR, el acreedor no tiene derecho a reclamar la indemnización de daños o aquella suma de dinero estipulada para el incumplimiento (indemnización convencional o cláusula penal) en la medida en que hubiere incrementado las pérdidas o la suma pactada, por insistir en el cumplimiento específico, en circunstancias en que el acreedor podría haber celebrado razonablemente una operación de reemplazo sin un esfuerzo o costos significativos ${ }^{26}$.

v. En la CESL, el límite se prevé bajo dos modalidades: a) Para las compraventas entre comerciantes, el artículo 110 (3) ${ }^{27}$ limita esta pretensión si los costos o esfuerzos que impone al vendedor fueren desproporcionados respecto del beneficio que podría obtener el comprador; o b) para las compraventas de consumo, el artículo 111 (1) ${ }^{28}$ no procedería cuando después de comparar la pretensión de cumplimiento específico con otras opciones del comprador, aparezca que aquella impone al deudor unos costos desproporcionados en consideración (a) al valor que hubiere tenido la prestación conforme al contrato; (b) la significancia del incumplimiento; y (c) a que disponga de otro remedio cuyo ejercicio no implique al acreedor inconvenientes significativos.

También hemos de considerar la solución de otro modelo más cercano al nuestro, el de los Principios Latinoamericanos de Derecho de Contratos (PLDC) que, al establecer este límite, no solo considera los costes que el cumplimiento impone al deudor, sino también la posibilidad de satisfacción del interés del acreedor por otro medio. Pensamos en el artículo 94, en su última versión ${ }^{29}$, que reza como sigue: “(2) Tratándose de obligaciones no dinerarias, el cumplimiento específico se sujeta a las limitaciones siguientes: (a) No procede cuando el cumplimiento sea imposible (...); (b) Aun siendo posible el cumplimiento específico, este no procede cuando resultare extremadamente gravoso para el deudor, teniendo en cuenta que el acreedor puede satisfacer su interés con otro medio de tutela”.

\section{A modo de síntesis}

De una revisión del derecho uniforme, europeo y, también, latinoamericano de contratos, podemos extraer las siguientes conclusiones: (1) que el límite económico se activa, tanto para la falta de cumplimiento, como para los cumplimientos imperfectos o de falta de conformidad, excepto en la CISG, que lo circunscribe a esta última; (2) que, en algunos ordenamientos, puede actuar aisladamente siendo suficiente que el cumplimiento imponga al deudor un coste no razonable; en cambio, en otros, se requiere atender, además, a si el acreedor dispone de alguna otra alternativa razonable de satisfacción, como una operación de reemplazo o de cualquier otro remedio que no le represente inconvenientes significativos. En el primer caso, la pretensión de cumplimiento específico se sujeta a un límite económico representado por una desproporción absoluta de la ejecución, esto es, que en sí ella impone unos costos excesivos al deudor; y en el segundo, por una desproporción relativa que se traduce en que el límite económico operaría solo en la medida en que el acreedor no disponga de otro medio, cuyo ejercicio sea razonable e igualmente idóneo para la satisfacción de su interés. En el CESL se identifican marcadamente estas dos aproximaciones: la desproporción absoluta (artículo 110 (1)); y la relativa (artículo 111) ${ }^{30}$. Algo similar, aunque no tan marcado, se observa en los PICC, PECL y DCFR, no así en las Propuestas españolas ${ }^{31}$, ni en la reforma francesa, que directamente recogen la fórmula de la desproporción absoluta.

Entonces, el límite a la pretensión de cumplimiento puede configurarse en términos absolutos o relativos, sin ser irrelevante inclinarnos por una u otra forma de entenderlo. Según la primera, la pretensión es improcedente cuando su ejercicio en sí impone al deudor costos excesivos o no razonables en comparación con el beneficio que el cumplimiento reporta al acreedor. En cambio, de acuerdo a la otra, hemos de atender no solo a los costes del cumplimiento específico y al mencionado beneficio para el acreedor, sino también a si este dispone de otro remedio - menos gravoso para el deudor-, igualmente idóneo para satisfacer su interés. 
La cuestión, entonces, es ¿qué criterio resulta más acorde a la idea de una equilibrada y razonable protección del interés del acreedor, que presta atención, también al del deudor? En otras palabras, a la razonable gestión de los efectos del incumplimiento que la buena fe objetiva impone al acreedor ${ }^{32}$.

A nuestro juicio, el límite económico absoluto, como se ha presentado, pone en serio riesgo y debilita la fuerza obligatoria, principio rector de nuestro derecho contractual. Sobre todo que, ante la ausencia de la disciplina de la imprevisión por excesiva onerosidad y sus remedios, unido al rechazo sistemático por parte de nuestra justicia ordinaria, tal comprensión del límite abriría la puerta para aquellos deudores que, habiendo infringido el contrato, se opongan a esta pretensión, alegando como excusa su coste excesivo, con lo cual burlan las estrictas exigencias de la imprevisión contractual ${ }^{33}$. Entonces, admitir el límite económico absoluto implicaría prescindir del interés del acreedor y centrarnos exclusivamente en la posición del deudor, en circunstancias en las cuales su interés no es suficiente para sacrificar derechamente el interés del acreedor, cuya satisfacción es el fin último que todo contrato garantiza, con prescindencia del remedio que ejercite.

Por esta razón, siendo consecuente con el fundamento que permitiría incorporar este límite por vía jurisprudencial, su aceptación debiera, necesariamente, conciliar los intereses en juego: del acreedor afectado y del deudor incumplidor. Así las cosas, el límite a la pretensión de cumplimiento obliga, ante todo, a prestar atención al interés del acreedor, al que solo se le privará de ella cuando imponga al deudor costos excesivos, disponiendo de otra opción razonable y, menos costosa, igualmente apta para la realización de su propósito fracturado por el incumplimiento. Entonces, desde esta óptica, es insuficiente tomar en cuenta solo el costo económico - si este supera o no el valor de la prestación, o si tal costo no redunda en un beneficio económicosignificativo para el acreedor-, sino que hace falta, también, considerar la efectiva posibilidad de satisfacción del interés del acreedor.

Como anticipamos, el artículo 94 PLDC recoge el límite en su comprensión relativa, al activarse cuando el cumplimiento resultare excesivamente gravoso para el deudor, habida cuenta de que el acreedor podía, igualmente, satisfacer su interés por otro medio de tutela y a un menor costo.

De todo lo expresado, se sigue que, en esta última aproximación, si el acreedor no dispone de otro remedio para la satisfacción de su interés contractual, cuyo ejercicio sea razonable atendidas las circunstancias, el juez deberá acoger la pretensión de cumplimiento, sin atender a los costos excesivos que pudiera imponer al deudor, a quien no le quedaría otra alternativa que cumplir lo pactado. Es evidente la colisión entre los dos principios generales de la contratación, el de la fuerza obligatoria, que justifica y ordena el cumplimiento; y el de la buena fe objetiva, que actúa como freno del mismo, pese a lo pactado. Y el criterio que resuelve esta colisión, en la comprensión relativa del límite en estudio, es el del interés contractual. Por esta razón, no por otra, si no existe alternativa razonable, prevalece la fuerza obligatoria y, de paso, la protección del interés del acreedor.

Pensemos en las cañerías del caso 2.

Si estas, pese a la falta de conformidad del cumplimiento, son igualmente idóneas para satisfacer el interés del acreedor e insiste en la corrección del cumplimiento imperfecto, siendo que la indemnización de daños o la rebaja del precio, igualmente le permiten alcanzar la satisfacción de su interés, aplicaría el límite relativo y la pretensión se rechazará. El hecho de que el acreedor insista en un cumplimiento excesivamente costoso en tales circunstancias, implica una conducta contraria a la buena fe objetiva. En cambio, si en el mismo caso, las mencionadas cañerías no sirven, sea porque no son aptas para el uso doméstico o porque no se ajustan a la norma constructiva, la solución varía. No obstante que la corrección sea excesivamente costosa, prevalecerá la protección del interés del acreedor y el contratista será condenado, tal como lo exigió el acreedor, a la sustitución de las cañerías siendo absolutamente irrelevante los costos que implique al primero. Se privilegia la fuerza obligatoria y la buena fe no alcanza a erigirse como argumento suficiente para sacrificarla, ni menos para privilegiar la protección del contratista.

Recapitulando, advertimos que el solo hecho de que el cumplimiento específico imponga al deudor costes excesivos no resulta suficiente para frenar el derecho del acreedor a lo pactado; se requiere otro ingrediente 
gravitante, a saber: que el acreedor disponga de otro remedio. No siendo el caso, al deudor solo le queda cumplir y así lo declarará el juez en su sentencia de condena.

Habiendo delineado los contornos del límite económico y la forma de operar, debemos prestar atención a la imprevisión y, de esta forma, fijar el deslinde entre el primero y esta última.

\section{La imprevisión}

$\mathrm{Al}$ igual que el límite de los costos excesivos, la imprevisión no tiene un reconocimiento expreso en Chile. Si bien la doctrina mayoritaria argumenta, con mayor o menor amplitud, a favor de su admisión en nuestro derecho privado, la Corte Suprema la ha rechazado expresamente ${ }^{34}$. Lo anterior, sin embargo, no ha impedido que fallos de Cortes de Apelaciones la hayan acogido, aun cuando los supuestos a los cuales se ha aplicado y los fundamentos de tales fallos sean bastante criticables ${ }^{35}$. Por otra parte, la jurisprudencia arbitral se ha mostrado más abierta a aceptarla, al igual que la jurisprudencia administrativa ${ }^{36}$.

Sin embargo, como sabemos, la tendencia en el derecho contemporáneo es la de aceptar la imprevisión, como aparece de la revisión de los códigos civiles de los siglos XX y XXI y de los instrumentos de derecho contractual uniforme y armonizado. Así, los PICC, ${ }^{37}$ los PECL ${ }^{38}$ y el DCFR ${ }^{39}$ prevén la imprevisión contractual en términos amplios, al igual que el CESL ${ }^{40}$. Adicionalmente, hemos de considerar que la versión definitiva de los PLDC también la incorpora ${ }^{41}$. En el ámbito legal, cabe consignar que en Europa la consagran, entre otros, los Códigos Civiles de Italia (1942), Grecia (1946), Portugal (1967), Holanda (1992), Alemania (2002) y sorprendentemente, la reciente reforma al Código Civil francés (2016) ${ }^{42}$. En Latinoamérica, se la reconoce en los Códigos Civiles de Bolivia (1976), Perú (1984), Paraguay (1987), Brasil (2002) y Argentina (2015) y, además, el Código de Comercio colombiano (1971).

También - como en el caso del límite de los costos excesivos- la imprevisión deja al descubierto la tensión existente entre la fuerza obligatoria del contrato y la buena fe objetiva, manifestándose de manera más pronunciada, al constituir una excusa al cumplimiento del contrato, esto es, como una causa justificativa del incumplimiento del deudor, tal como ocurre con el caso fortuito o el hecho del acreedor, sin perjuicio de que la imprevisión genera, como se explicará, unos efectos diversos, que se materializan en el reconocimiento a favor del deudor afectado, orientados a restablecer - aunque parcialmente - el equilibrio del contrato, e incluso a dejarlo sin efecto.

La amplia aceptación de la imprevisión en el derecho comparado y también, en cierta medida, en nuestra jurisprudencia arbitral y administrativa, justifica sobradamente la necesidad de delimitarla o diferenciarla de los costos excesivos, tarea de la que nos ocuparemos en los párrafos siguientes.

Un concepto amplio de imprevisión

Como primera cuestión a resolver, debemos despejar acerca de la comprensión de la imprevisión que es, precisamente, la que lleva a su confusión con el límite económico del cumplimiento específico, definición que permitirá situar cada una de estas reglas en su lugar respectivo.

La zona de confusión se origina respecto de la idea tradicional y restringida de la imprevisión, propia de los ordenamientos de influencia francesa. En ella, la imprevisión comprende solo aquel supuesto en el que, debido a circunstancias imprevistas y sobrevinientes a la celebración del contrato, para una de las partes, la ejecución del contrato en los términos pactados originalmente deviene en excesivamente onerosa y la hace extremadamente gravosa o difícil para ella43.

Sin embargo, la concepción que hoy predomina en el derecho contractual es más amplia, al no agotarse al de la excesiva onerosidad sobrevenida, sino extendiéndose al caso en que el valor o utilidad de la contraprestación, también por causas imprevistas y sobrevenidas, disminuye significativamente para el acreedor.

En esta concepción amplia, comprensiva de las dos hipótesis, la imprevisión se justifica en nuevas circunstancias - extraordinarias e imprevisibles al tiempo del contrato- que provocan un grave desequilibrio 
en su economía, y que se recoge por el derecho uniforme y armonizado. Así, el citado artículo 6.2.2 de los PICC estipula que "Hay 'excesiva onerosidad' (hardship) cuando el equilibrio del contrato es alterado de modo fundamental por el acontecimiento de ciertos eventos, bien porque el costo de la prestación a cargo de una de las partes se ha incrementado, o porque el valor de la prestación que una parte recibe ha disminuido".

En la extensión del ámbito de imprevisión, el contratante afectado es el acreedor, quien recibirá a cambio de su propia prestación, una contraprestación carente de valor o utilidad o significativamente de menor entidad, lo que se conoce con la denominación de frustración del contrato o frustration of purpose ${ }^{44}$. Para ilustrar este caso, pensemos en un importador de repuestos para automóviles que compra una gran cantidad de filtros, que disminuyen considerablemente la contaminación proveniente de motores diésel y permite cumplir la nueva norma nacional para la circulación de los vehículos con tales motores. Celebrada la compraventa, la autoridad deroga la norma por razones imprevistas al tiempo del contrato, haciendo desaparecer el mercado para tales filtros y generando un grave perjuicio económico al comprador - importador - habida cuenta de que, no obstante seguir obligado a recibir los filtros y pagar su precio, no podrá comercializarlos.

Se observa en el ejemplo propuesto que el cumplimiento del contrato es perfectamente posible para el importador, ya que su obligación (pagar el precio) no se ha tornado más gravosa. No obstante, la prestación que recibe a cambio de dicho cumplimiento (la entrega de los filtros), ha perdido valor para él por la desaparición del mercado de los filtros. Planteado de otra forma, se ha frustrado el propósito práctico del importador, siendo justificado el reconocimiento de los remedios propios de la imprevisión.

El artículo 85 (De la frustración de la causa del contrato) de los PLDC reconoce, oblicuamente, esta manifestación de la imprevisión al disponer que "La frustración definitiva de la causa por un cambio de circunstancias existentes a la época de la perfección, imprevisto para las partes y que supera el riesgo asumido por aquella afectada, la autoriza a resolverlo".

Si miramos despacio el caso presentado para ilustrar esta segunda dimensión de la imprevisión frustración del propósito del contrato-, hemos de coincidir que en ella no hay posibilidad de confusión con el límite económico de la pretensión de cumplimiento. No hay un problema de mayor coste, sino de una disminución significativa para una de las partes de la utilidad o beneficio a que tenía derecho a esperar en virtud del contrato.

Llegados a este punto, ¿qué conclusión podemos extraer?

Que, si consideramos el ámbito actual de la imprevisión, el espacio de posible confusión con el tantas veces mencionado límite económico, se reduce a aquellos supuestos de excesiva onerosidad sobrevenida como excusa del cumplimiento.

Hecha esta precisión, nuestro interés se centrará en este supuesto de imprevisión, en el que sí pueden producirse problemas de deslinde con el límite económico tantas veces aludido.

La imprevisión como excusa. Oportunidad y condiciones de procedencia

Fijemos ahora nuestra atención en los elementos que permiten separar las dos reglas en cuestión, para determinar su ámbito de aplicación y efectos.

Primeramente, así lo anticipamos, el ámbito temporal de la imprevisión difiere de aquel del límite económico. La primera se sitúa antes del cumplimiento, no obstante su exigibilidad; en cambio, el segundo se activa una vez producido el incumplimiento, en la fase de los remedios del acreedor. Efectivamente, la imprevisión se ubica entre la celebración del contrato y su ejecución y actúa como una excusa del cumplimiento que priva al acreedor de su derecho de exigirlo tal como fue pactado. En cambio, los costos excesivos aplican como límite en la fase del ejercicio de los remedios a la infracción contractual y excluyen la procedencia del cumplimiento específico.

Si volvemos a los casos, si bien en ambos resulta evidente que la regla incide en el cumplimiento del contrato, al limitar o excluir el derecho del acreedor, lo hace en momentos distintos. Y no solo eso, sino que también de diversa forma y cada uno con sus propias condiciones y efectos. Volvamos a los casos. 
En el primero, las circunstancias que hacen excesivamente más onerosa la ejecución del contrato son la salida del Reino Unido de la Unión Europea y la decisión gubernamental de Estados Unidos, al provocar un alza en el precio del dólar en moneda local y el consecuente incremento desproporcionado de los costes de ejecución del contrato. Se genera un nuevo escenario, en que, si bien el cumplimiento igualmente es objetiva y jurídicamente - posible, realizarlo según lo pactado resulta al deudor excesivamente más oneroso en comparación con los costes previsibles inicialmente. Por esta última razón, y no otra, a la parte afectada se la excusa de cumplir, quedando facultada, si es el caso, a hacerlo, pero ahora en otros términos; aquellos que resulten de la adaptación del contrato a las nuevas circunstancias.

En la imprevisión, debemos indagar sobre la causa del aumento extraordinario de los costes de ejecución y que refiere a un cambio fundamental de las circunstancias, razonablemente imprevisible para el deudor al momento del contrato, en términos que de haberlo previsto no habría contratado o lo habría hecho en otras condiciones. El deudor no asumió, al contratar, el riesgo del cambio de circunstancias y el subsecuente incremento de los costos del cumplimiento. Si bien la imprevisión tiene una explicación económica, ella solo persigue proteger el interés del deudor afectado por la fractura imprevisible de la economía del negocio, sin que sea relevante el interés del acreedor en el cumplimiento del contrato. Basta la concurrencia de las condiciones de la imprevisión para activar la excusa y los remedios que le son propios.

En cambio, tratándose del límite económico, en nada incide la causa u origen del costo excesivo del cumplimiento específico; basta constatarlo. Sin embargo, lo anterior no es suficiente, hace falta aún considerar la posición del acreedor, particularmente, si tiene o no otra posibilidad para la satisfacción de su interés. Si no, prevalece el contrato y la protección del acreedor, con lo cual queda al margen la protección del interés del deudor que deberá cumplir no obstante el excesivo costo de la corrección. Así las cosas, si bien el límite aludido constituye una defensa a favor del interés del deudor, no posee el poder suficiente para sacrificar el interés del acreedor, que en esta sede - la del incumplimiento - deberá siempre quedar satisfecho, incluso, si es el caso, a través de una ejecución excesivamente costosa.

Entonces, en ambas hipótesis, es insuficiente atender al costo económico que el cumplimiento representa para el deudor, aunque sí actúa como un elemento que nos permite hilvanar ambas reglas. Hemos de atender, además, en el caso de la imprevisión, a si el cambio de circunstancias que provocó el incremento económico era razonablemente imprevisible y si el deudor asumió o no el riesgo de su acaecimiento; y en el caso de los costos excesivos, a si el acreedor dispone de otro medio para la realización de su interés. Si planteamos las cosas en términos más simples, en la imprevisión la regla mira al interés del deudor, pudiendo llegar a descartar — como diremos- el del acreedor (si procede la resolución del contrato); en cambio, en el cumplimiento específico, se pondera el interés de ambos intereses, no estando permitido, en ningún caso, sacrificar el del acreedor. $\mathrm{O}$ sea, en la primera, prevalece la protección del interés del deudor; en la segunda, la del interés del acreedor.

Otro aspecto a destacar, como tercer ámbito a distinguir, que permite la delimitación del ámbito de ambas reglas, refiere a la función que cumple la buena fe. A falta de norma expresa, encontramos el fundamento de la imprevisión y de los costes excesivos en el principio de la buena fe del artículo 1546 Código Civil. Sin embargo, dicho principio se desenvuelve respecto de cada uno de distinta manera, aunque siempre justificando y fijando un freno a la fuerza obligatoria del contrato o, si se prefiere, al derecho a exigir el cumplimiento. Pero la función que le cabe a este principio rector difiere según sea el caso.

En la imprevisión, la buena fe justifica y explica, a pesar de la fuerza obligatoria, de una parte, que el deudor queda dispensado de cumplir lo pactado, excusando su incumplimiento; y, de otro, la privación del derecho del acreedor a exigir el cumplimiento de lo pactado. El ejercicio de tal derecho contraría las exigencias que impone este principio, toda vez que el admitirlo se resolvería en aceptar la imposición al deudor de un gravamen económico tal, que ni él ni una persona razonable en su lugar pudo tener en cuenta o prever al momento de contratar, y que, por tanto, no hay razón que justifique que deba soportarlo.

En la hipótesis del costo excesivo del cumplimiento específico, la buena fe también limita el ejercicio del derecho a reclamarlo; sin embargo, como hemos explicado, situamos tal limitación en lo que se denomina el 
razonable ejercicio de los remedios al incumplimiento, que tiende a una equilibrada protección del interés del acreedor afectado y del deudor incumplidor. Precisamente, la buena fe es la que permite imponer cargas al acreedor y limitarle en el ejercicio de sus derechos o acciones (remedios). Así, en el caso que nos interesa, si el acreedor disponía de otro medio menos costoso e insiste en exigir lo pactado a un costo excesivo, estaría contrariando las exigencias de la buena fe aun cuando, conforme el contrato, sea titular, del derecho. Esta es la justificación de la improcedencia de la pretensión de cumplimiento ${ }^{45}$.

En definitiva, concurriendo las condiciones de procedencia de la imprevisión, el deudor queda excusado de cumplir y el acreedor privado de exigir la ejecución del contrato, porque de ser otra forma se traspasarían los límites de la buena fe objetiva. Y si es el caso, se abren paso los efectos propios de la imprevisión, ámbito en el que también afloran diferencias importantes con el límite económico del cumplimiento. Detengámonos en el régimen de remedios de la imprevisión con la finalidad de dibujar una diferencia más entre esta y el límite económico.

\section{El sistema de remedios para la imprevisión contractual}

La consideración de la imprevisión como excusa no debe llevarnos al equívoco de que su efecto siempre será liberar al deudor de cumplir. Al contrario, tanto en doctrina como en el derecho comparado y en el uniforme y armonizado de contratos, los efectos de la imprevisión se traducen en un complejo sistema de remedios, cuya finalidad primaria es la preservación del contrato, pero corrigiendo sus términos a través de una distribución del mayor costo sobrevenido — más allá de los riesgos razonablemente asumidos por el deudor al contratar46 ; y solo en caso de no ser posible, será procedente la aniquilación del contrato por medio de la resolución judicial.

En el derecho uniforme, el artículo 6.2.3 de los PCCI refleja claramente lo expresado, al prever como remedios a la excesiva onerosidad el derecho de la parte en desventaja a reclamar la renegociación del contrato y, para el caso de no existir acuerdo, se reconoce a ambas partes el derecho a solicitar al juez la adaptación o la resolución del mismo. Los PECL y el DCFR recogen normas similares, al igual que las legislaciones como la holandesa y alemana.

Podemos mostrar la complejidad del sistema de remedios de la imprevisión recurriendo al nuevo artículo 1195 del Código Civil francés, norma que reconoce por primera vez, en dicho ordenamiento, la imprevisión en contratos de derecho privado. La disposición, con notoria influencia del derecho uniforme, dispone, como primer efecto de la imprevisión, el derecho de la parte afectada a solicitar la renegociación del contrato; y, en caso de negativa de la contraparte o de fracaso de las renegociaciones, las partes pueden resolver el contrato o de mutuo acuerdo, solicitar su adaptación al juez. En este último caso, a falta de acuerdo de las partes dentro de un plazo razonable, el juez podrá, a petición de cualquiera de ellas, revisar el contrato o ponerle término, en la fecha y condiciones que determine.

El primer efecto de la imprevisión es el deber de renegociar el contrato de buena fe, cuya finalidad es que las partes lo adapten - sus condiciones - a las nuevas circunstancias. El deber pesa sobre ambas partes y si no alcanzan el resultado corrector esperado, cualquiera de las partes dispone de la facultad de pedir la modificación —adaptación - o resolución del contrato ${ }^{47}$. Nuevamente, aflora la diferencia entre la imprevisión y los costos excesivos: el deber de renegociar. Si concurre el supuesto del límite, simplemente el cumplimiento no tendrá lugar; sí otro cualquiera de los remedios del acreedor.

Sin embargo, punto que marca la distancia en esta materia concierne a que en la imprevisión si la renegociación fracasa, las partes tienen la facultad de solicitar al juez que adapte el contrato a las nuevas circunstancias o que lo resuelva; y si se produce la adaptación en términos razonables para los interesados, el deudor quedará obligado a ejecutar la prestación en estos nuevos términos. 
Si volvemos al caso 1 , ante el alza desmesurada de los costos en los materiales, la constructora podría solicitar la revisión del contrato por el juez, con el propósito de que se modificase el precio originalmente pactado para ajustarlo a las nuevas condiciones del mercado. La fuerza obligatoria se ve afectada ya que si bien el contrato debe cumplirse - tras la adaptación-, será en términos diversos a los originalmente acordados.

Por esta razón, si bien la imprevisión se traduce en una excusa de cumplir en los términos originalmente pactados, el contrato pervive pudiendo ser procedente su ejecución, pero en otros términos a los pactados al celebrarlo, una vez restablecido su equilibrio inicial ${ }^{48}$.

Justamente ahí reside la diferencia con los costos excesivos, al no tratarse de un problema de alteración sobrevenida de las circunstancias, sino simplemente de un caso en el que los costos de la corrección del incumplimiento - en nuestro ejemplo, la instalación correcta de las cañerías - implica unos costes que no son razonables en atención al interés del acreedor en el cumplimiento exacto.

Finalmente, como hemos anticipado, en la imprevisión, si no es posible restaurar el equilibrio contractual —renegociación o adaptación judicial—, procede la resolución o terminación del contrato. En cambio, en los costos excesivos si se activa el límite, el contrato se conserva, pero al acreedor se le priva del derecho a hacer cumplir lo pactado, es decir, satisfacer su interés en naturaleza, sin embargo, puede ejercitar cualquiera de los otros remedios, como la indemnización de daños, la reducción del precio o la misma resolución seguida de una operación de reemplazo, pero esta última no en razón o como causa del mayor coste del cumplimiento, sino como un cauce idóneo para satisfacer su interés positivo (en el cumplimiento) ${ }^{49}$.

En definitiva, queremos poner de relieve que si bien en la imprevisión el deudor queda excusado de cumplir en los términos pactados, al subsistir el contrato, igualmente puede quedar obligado a ejecutarlo, aunque bajo otras condiciones, a menos que proceda la resolución, en cuyo caso sí se libera... pero porque el contrato se extingue. En cambio, en el costo excesivo, el deudor se libera del cumplimiento, pero como siempre el contrato subsiste, igualmente queda expuesto a los remedios del acreedor enderezados a la satisfacción de su interés.

\section{Conclusiones}

1. Actualmente se prevén, por vía normativa, doctrinal y jurisprudencial, límites al cumplimiento del contrato, en particular, la excesiva onerosidad sobrevenida o imprevisión y los costos excesivos del cumplimiento específico.

2. Sin embargo, la doctrina no ha logrado explicar con claridad la diferencia o frontera entre ambos límites, y se advierte que ella incurre en confusiones conceptuales importantes que crean incertidumbre en los operadores del tráfico: contratantes, jueces y árbitros.

3. Un estudio detenido de ambas reglas, la de imprevisión y la del límite económico, permite marcar esta diferencia o frontera con bastante claridad, siendo los aspectos más relevantes que así lo muestran: a. El ámbito de aplicación de la imprevisión es más amplio que el de los costos excesivos, ya que el concepto de imprevisión incluye también el supuesto de pérdida significativa del valor de la prestación que se tiene derecho a exigir, hipótesis por completo ajena a los costos excesivos como límite al cumplimiento.

a) El ámbito de aplicación de la imprevisión es más amplio que el de los costos excesivos, ya que el concepto de imprevisión incluye también el supuesto de pérdida significativa del valor de la prestación que se tiene derecho a exigir, hipótesis por completo ajena a los costos excesivos como límite al cumplimiento.

b) El ámbito de aplicación temporal de la imprevisión difiere del de los costos excesivos, ya que la primera se sitúa en un momento entre la celebración del contrato y su ejecución, actuando como una excusa para el deudor. Por su parte, los costos excesivos aplican como 
límite ya producido el incumplimiento contractual, en la fase de ejercicio de los remedios al mismo, excluyendo el ejercicio de la pretensión de cumplimiento específico.

c) Cada una de las instituciones en comento tiene sus propias condiciones de procedencia. La imprevisión requiere un cambio razonablemente imprevisible de circunstancias, que transforme en excesivamente onerosa la prestación y que el deudor no haya asumido el riesgo de tales circunstancias. Se protege el interés del deudor afectado, siendo irrelevante el interés del acreedor en el cumplimiento del contrato, salvo que se alcance la renegociación o adaptación de sus términos. Por otra parte, en el límite económico, la causa del costo excesivo es irrelevante; sin embargo, este no es suficiente, siendo menester, además, que el acreedor disponga de otro remedio, distinto de la pretensión de cumplimiento específico, igualmente apto para la satisfacción de su interés.

d) Los efectos de la imprevisión difieren de los de los costos excesivos. Admitida la imprevisión como excusa, se da lugar a un complejo sistema de remedios que tiene por objeto restaurar, hasta cierto límite, el equilibrio contractual perdido. Este sistema incluye el deber de renegociar el contrato, así como su posible adaptación por el juez o, en último caso, la terminación del mismo. La configuración como excusa de la imprevisión no excluye que el deudor, renegociado o adaptado el contrato, deba cumplir el contrato en los términos modificados. Los costos excesivos, en cambio, simplemente excluyen el cumplimiento específico como remedio para el acreedor, quedando a salvo su derecho a recurrir - si se cumplen los requisitos de procedencia respectivos- a los otros remedios que el ordenamiento jurídico pone a su disposición para el caso de incumplimiento contractual, con el objeto de satisfacer plenamente su interés.

\section{Bibliografía}

$\cdots$

\section{Libros}

ABELIUK-MANASEVICH, RENÉ, Las obligaciones (4a ed. actualizada, Editorial Jurídica de Chile, Santiago, 2003). Asociación de Profesores de Derecho Civil de España, Propuesta de Código Civil, Libros Quinto y Sexto (Tirant lo Blanch, Valencia, 2016).

BOETSCH-GILLET, CRISTIÁN, La buena fe contractual (Editorial Jurídica, Santiago, 2011).

BRANTT-ZUMARÁN, MARÍA GRACIELA, El caso fortuito y su incidencia en el derecho de la responsabilidad civil contractual: concepto y función del caso fortuito en el Código Civil chileno (Publicaciones Profesionales, Santiago de Chile, 2010).

BRUNNER, CHRISTOPH, Force Majeure and Hardship under General Contract Principles (Kluwer Law International, The Hague, 2008).

BURROWS, ANDREW, Remedies for Torts and Breach of Contract (Oxford University Press, Oxford, 2004).

FERREIRA-RUBIO, DELIA MATILDE, La buena fe. El principio general en el derecho civil (Montecorvo, Madrid, 1984).

FUEYO-LANERI, FERNANDO, Instituciones de Derecho Civil moderno (Editorial Jurídica de Chile, Santiago, 1990).

ILLANES, CLAUDIO \& DÖRR, JUAN CARLOS, Estudios sobre Reformas al Código Civily al Código de Comercio, 221-242 (Editorial Jurídica de Chile, Santiago de Chile, 2000). 
MAZA-GAZMURI, ÍNIIGO DE LA; PIZARRO-WILSON, CARLOS \& VIDAL-OLIVARES, ÁLVARO, Los principios latinoamericanos de derecho de los contratos, una primera aproximación (Colección Derecho Privado, BOE, Boletín Oficial del Estado, Madrid, 2017).

MOZOS, JOSÉ LUIS DE LOS, El principio de la buena fe. Sus aplicaciones prácticas en Derecho Civil español (Bosch, Barcelona, 1965).

SACCO, RODOLFO \& DE NOVA, GIORGIO, Il contratto (Unione Tipografico-Editrice Torinese, UTET, Torino, 2004).

SCHLECHTRIEM, PETER, Uniform Sales Law, The UN Convention on Contracts for the International Sale of Goods (Manz, Vienna, Austria, 1986). Disponible en: https://www.cisg.law.pace.edu/cisg/biblio/schlechtriem.html

ZIMMERMANN, REINHARD, The New German Law of Obligations: Historical and Comparative Perspectives (Oxford University Press, Oxford, 2005).

\section{Contribuciones en obras colectivas}

BAHAMONDES-OYARZÚN, CLAUDIA, La concurrencia de la indemnización de daños y la pretensión de cumplimiento especifico frente al incumplimiento del deudor, en Cuadernos de análisisjurídico. Colección de Derecho Privado VII, Incumplimiento contractual: nuevas perspectivas, 235-262 (ÍNIGO DE LA MAZA-GAZMURI, coord., Ediciones Universidad Diego Portales, Santiago de Chile, 2011). Disponible en: http://fundacionfueyo .udp.cl/cuadernos-de-analisis-juridico/

CABANILLAS-SÁNCHEZ, ANTONIO, Artículo 28 CISG, en La compraventa internacional de mercaderías, Comentario de la Convención de Viena, 229-234 (LUIS DÍEZ PICAZO Y PONCE DE LEÓN, dir. y coord., Civitas, Madrid, 1998).

MOMBERG-URIBE, RODRIGO, Análisis critico desde el derecho alemán y nacional de la sentencia de la Corte de Apelaciones de Santiago que acoge la teoria de la imprevisión, en Estudios de Derecho Civil III, 637-658 (ALEJANDRO GUZMÁN-BRITO, ed., Legal Publishing, Santiago, 2008).

MOMBERG-URIBE, RODRIGO, El sistema de remedios para el caso de imprevisión o cambio de circunstancias, en Cuadernos de análisis jurídico. Colección de Derecho Privado VII, Incumplimiento contractual: nuevas perspectivas, 83-105 (ÍNIIGO DE LA MAZA-GAZMURI, coord., Ediciones Universidad Diego Portales, Santiago de Chile, 2011). Disponible en: http://fundacionfueyo.udp.cl/cuadernos-de-analisis-juridico/

MÜLLER-CHEN, MARKUS, Commentary on the Art. 46 CISG, en Commentary on the UN Convention on the International Sales of Goods (CISG), 705-723 (PETER SCHLECHTRIEM \& INGEBORG SCHWENZER, eds., Oxford University Press, Oxford, 2005).

SCHELHAAS, HARRIET, Comment to Arts. 7.2.1-7.2.5 (Right to performance), en Commentary on the UNIDROIT Principles of International Commercial Contracts (PICC), 881-915 (STEFAN VOGENAUER, ed., Oxford University Press, Oxford, 2015).

VIDAL-OLIVARES, ÁLVARO, El incumplimiento contractual y pretensión de cumplimiento especifico en los Principios Latinoamericanos de Derecho de Contratos (PLDC), en El derecho común europeo de la modernización del derecho de contratos, 745-768 (ANTONI VAQUER-ALOY, ESTEVE BOSCH-CAPDEVILA \& MARÍA PAZ SÁNCHEZ-GONZÁLEZ, dirs., Atelier Libros Jurídicos, Barcelona, 2015).

VIDAL-OLIVARES, ÁLVARO, La carga de mitigar las pérdidas del acreedor y su incidencia en el sistema de remedios por incumplimiento, en Estudios de Derecho Civil III, Jornadas Nacionales de Derecho Civil, Valparaiso, 2007, 429-457 (ALEJANDRO GUZMÁN-BRITO, ed., Legal Publishing, Santiago, 2008).

VIDAL-OLIVARES, ÁLVARO, La pretensión de cumplimiento especifico de las obligaciones no dinerarias y los costes excesivos para el deudor como limite a su ejercicio, en Estudios de Derecho Civil IX, 555-578 (Legal Publishing Thomson Reuters, Valparaíso, 2015).

VIDAL-OLIVARES, ÁLVARO, La pretensión de cumplimiento especifico y su inserción en el sistema de remedios por incumplimiento en el Código Civil, en Estudios de Derecho Civil II, 517-537 (HERNÁN CORRAL-TALCIANI 
\& MARÍA SARA RODRÍGUEZ-PINTO, coords., IV Jornadas Nacionales de Derecho Civil, Olmué, 3-5 de agosto de 2006, LexisNexis, Santiago de Chile, 2007).

ZOLL, FRYDERYK, European Contract Law, en Common European Sales Law (CESL), A Commentary, 506-510 (REINER SCHULZE, ed., Beck, Hart, Nomos, Oxford, 2012).

\section{Artículos de revistas}

CORRAL-TALCIANI, HERNÁN, La aplicación jurisprudencial de la buena fe objetiva en el ordenamiento civil chileno, 12-13 Revista de Derecho Privado de la Universidad Externado de Colombia, 143-178 (2007). Disponible en: https://revistas.uexternado.edu.co/index.php/derpri/article/view/563/533

DÖRR, JUAN CARLOS, Notas acerca de la teoria de la imprevisión, V Revista Chilena de Derecho, 12, 253-270 (1985). Disponible en: https://repositorio.uc.cl/handle/11534/11831

FENOY-PICÓN, NIEVES, La modernización del régimen del incumplimiento del contrato: propuestas de la Comisión General de Codificación. Parte segunda: los remedios por incumplimiento, LXIV Anuario de Derecho Civil, ADC, 4, 1481-1685 (2011). Disponible en: https://boe.es/publicaciones/anuarios_derecho/abrir_pdf.php?id=ANU-C-2011-40148101685_ANUA RIO_DE_DERECHO_CIVIL_La_Modernizaci\%F3n_del_r\%E9gimen_del_incumplimiento_del_contrato: _propuestas_de_la_Comisi\%F3n_General_de_Codificaci\%F3n._Parte_Segunda:_los_remedios_por_incump limiento

GUZMÁN-BRITO, ALEJANDRO, La buena fe en el Código Civil de Chile, 29 Revista Chilena de Derecho, 1, 11-23 (2002). Disponible en: https://repositorio.uc.cl/bitstream/handle/11534/14884/000334614.pdf?sequence=1 \&isAllowed $=\mathrm{y}$

LANDO, OLE, Is Good Faith an Over-Arching General Clause in the Principles of European Contract Law?, 15 European Review of Private Law, 6, 841-853 (2007). Disponible en: https://www.kluwerlawonline.com/abstra ct.php?area=Journals\&id=ERPL2007048

LÓPEZ-DÍAZ, PATRICIA VERÓNICA, El abuso del derecho de opción del acreedor y su importancia en la construcción de un sistema equilibrado de remedios por incumplimiento contractual, 19 Revista Chilena de Derecho Privado, RChDP, 13-62 (2012). http://dx.doi.org/10.4067/S0718-80722012000200002. Disponible en: http s://scielo.conicyt.cl/pdf/rchdp/n19/art02.pdf

MOMBERG-URIBE, RODRIGO, La revisión del contrato por las partes: el deber de renegociación como efecto de la excesiva onerosidad sobreviniente, 37 Revista Chilena de Derecho, 1, 43-72 (2010). Disponible en: https://scielo .conicyt.cl/pdf/rchilder/v37n1/art03.pdf

MOMBERG-URIBE, RODRIGO, Teoría de la imprevisión: la necesidad de su regulación legal en Chile, 15 Revista Chilena de Derecho Privado, RChDP, 29-64 (2010). Disponible en: https://scielo.conicyt.cl/pdf/rchdp/n15/a rt02.pdf

PIZARRO-WILSON, CARLOS, Notas acerca de los limites a la pretensión de cumplimiento del contrato, 21 Revista de Derecho, Universidad Católica del Norte, RDUCN, 1, 203-219 (2014). Disponible en: https://scielo.conicy t.cl/pdf/rducn/v21n1/art06.pdf

SEVERIN-FUSTER, GONZALO, Sobre el carácter secundario y discrecional del remedio del cumplimiento especifico en el common law. Perspectiva histórica y aproximación actual, 43 Revista Chilena de Derecho, 1, 7-37 (2016). https ://dialnet.unirioja.es/descarga/articulo/5598304.pdf

VIDAL-OLIVARES, ÁLVARO, La gestión razonable de los efectos del incumplimiento en la compraventa internacional, XVIII Revista de Derecho de la Universidad Austral de Chile, 2, 55-81 (2005). http://dx.doi.org/10.4067/ S0718-09502005000200003. Disponible en : https://scielo.conicyt.cl/scielo.php?script=sci_arttext\&pid=S07 18-09502005000200003 


\section{Normatividad internacional}

Alemania, Código Civil, Bürgerliches Gesetzbuch, BGB, Boletín del Reich, 24 de agosto de 1896. Disponible en: http s://www.gesetze-im-internet.de/bgb/, https://www.gesetze-im-internet.de/bgb/BJNR001950896.html

Instituto Internacional para la Unificación del Derecho Privado, Unidroit, Principios sobre Contratos Comerciales Internacionales, PCCI. Disponible en: https://www.unidroit.org/spanish/principles/contracts/principles2010 /blackletter2010-spanish.pdf

\section{Normatividad chilena}

Chile, Código Civil, Ley de 14 de diciembre de 1855, Diario Oficial, 16 de mayo de 2000. Disponible en: https://ww w.leychile.cl/Navegar?idNorma $=172986 \&$ idParte $=8717776$

\section{Jurisprudencia chilena}

Chile, Corte Suprema, 09 de septiembre de 2009, South Andes Capital S.A. con Empresa Portuaria de Valparaíso, Rol 2651-08

\section{Notas}

1 Sobre la relación horizontal entre la pretensión de cumplimiento y la indemnización de daños, superando la tradicional jerarquía entre ambos remedios: CLAUDIA BAHAMONDES-OYARZÚN, La concurrencia de la indemnización de daños y la pretensión de cumplimiento especifico frente al incumplimiento del deudor, en Cuadernos de análisis jurídico. Colección de Derecho Privado VII, Incumplimiento contractual: nuevas perspectivas, 235-262 (ÍNIGO DE LA MAZA-GAZMURI, coord., Ediciones Universidad Diego Portales, Santiago de Chile, 2011). Unos años antes, con argumentos semejantes, para proponer una lectura conjunta de los artículos 1553 y 1489, ambos del Código Civil: ÁLVARO VIDAL-OLIVARES, La pretensión de cumplimiento especifico y su inserción en el sistema de remedios por incumplimiento en el Código Civil, en Estudios de Derecho Civil II, 517-537, 522-528 (HERNÁN CORRAL-TALCIANI \& MARÍA SARA RODRÍGUEZ-PINTO, coords., IV Jornadas Nacionales de Derecho Civil, Olmué, 3-5 de agosto de 2006, LexisNexis, Santiago de Chile, 2007).

2 ÁLVARO VIDAL-OLIVARES, La carga de mitigar las pérdidas del acreedor y su incidencia en el sistema de remedios por incumplimiento, en Estudios de Derecho Civil III, Jornadas Nacionales de Derecho Civil, Valparaiso, 2007, 429-457 (ALEJANDRO GUZMÁN-BRITO, ed., Legal Publishing, Santiago, 2008).

3 PATRICIA VERÓNICA LÓPEZ-DÍAZ, El abuso del derecho de opción del acreedor y su importancia en la construcción de un sistema equilibrado de remedios por incumplimiento contractual, 19 Revista Chilena de Derecho Privado, RChDP, 13-62 (2012). http://dx.doi.org/10.4067/S0718-80722012000200002

4 Esta tradición que aún se mantiene se observa en la Convención de las Naciones Unidas sobre los Contratos de Compraventa Internacional de Mercaderías (United Nations Convention on Contracts for the International Sale of Goods, CISG) que, frente al incumplimiento del deudor - vendedor y comprador-, reconoce al acreedor, ante todo, el derecho al cumplimiento específico (artículos 45.1 y 61.1), sin embargo, como una muestra del compromiso entre dos sistemas, el de derecho civil continental y el del common law, se introduce la regla del artículo 28. Sobre el fundamento o, más bien, la explicación de la regla: ANTONIO CABANILLAS-SÁNCHEZ, Artículo 28 CISG, en La compraventa internacional de mercaderias, Comentario de la Convención de Viena, 229-234, 231-233 (LUIS DÍEZ PICAZO Y PONCE DE LEÓN, dir. y coord., Civitas, Madrid, 1998). PETER SCHLECHTRIEM, Uniform Sales Law, The UN Convention on Contracts for the International Sale of Goods, 62-63 (Manz, Vienna, Austria, 1986). Como es sabido, en el common law la situación es la inversa: el cumplimiento específico solo se concederá excepcionalmente. Un muy buen trabajo en español sobre el remedio del cumplimiento específico en el common law es el de GONZALO SEVERIN-FUSTER, Sobre el carácter secundario y discrecional del remedio del cumplimiento especifico en el common law. Perspectiva histórica y aproximación actual, 43 Revista Chilena de Derecho, 1, 7-37 (2016). Para un análisis general del sistema de remedios del common law, ANDREW BURROWS, Remedies for Torts and Breach of Contract (Oxford University Press, Oxford, 2004). 
5 Sobre las condiciones de procedencia de la pretensión de cumplimiento específico y sus límites en el derecho uniforme y armonizado de contratos: ÁLVARO VIDAL-OLIVARES, El incumplimiento contractual y pretensión de cumplimiento especifico en los Principios Latinoamericanos de Derecho de Contratos (PLDC), en El derecho común europeo de la modernización del derecho de contratos, 745-768 (ANTONI VAQUER-ALOY, ESTEVE BOSCH-CAPDEVILA \& MARÍA PAZ SÁNCHEZGONZÁLEZ, dirs., Atelier Libros Jurídicos, Barcelona, 2015). Y en el derecho civil chileno sin norma expresa: ÁLVARO VIDALOLIVARES, La pretensión de cumplimiento especifico de las obligaciones no dinerarias y los costes excesivos para el deudor como limite a su ejercicio, en Estudios de Derecho Civil IX, 555-578 (Legal Publishing Thomson Reuters, Valparaíso, 2015). También CARLOS PIZARRO-WILSON, Notas acerca de los limites a la pretensión de cumplimiento del contrato, 21 Revista de Derecho, Universidad Católica del Norte, RDUCN, 1, 203-219 (2014).

6 Instituto Internacional para la Unificación del Derecho Privado, Unidroit, Principios sobre Contratos Comerciales Internacionales, PCCI.

7 HARRIET SCHELHAAS, Comment to Arts. 7.2.1-7.2.5 (Right to performance), en Commentary on the UNIDROIT Principles of International Commercial Contracts (PICC), 881-915 (STEFAN VOGENAUER, ed., Oxford University Press, Oxford, 2015).

8 Id.

9 REINHARD ZIMMERMANN, The New German Law of Obligations: Historical and Comparative Perspectives, 44-45 (Oxford University Press, Oxford, 2005). El ejemplo es el siguiente: un anillo, que debía entregarse en virtud de un contrato de compraventa, cae a un lago. El valor del anillo es $€ 100$. El anillo podría recuperarse a un costo de $€ 100.000$. Sería entonces irrazonable exigir al deudor el cumplimiento de la prestación (entregar el anillo), a un costo de $€ 100.000$, si el interés del acreedor en el cumplimiento del contrato puede reducirse al valor de la cosa $(€ 100)$. La doctrina alemana distingue esta situación de la imposibilidad absoluta, en la cual no es posible ejecutar la prestación bajo ninguna circunstancia. Sin embargo, como se dijo, esa distinción no es para nítida, y el caso planteado podría también encuadrarse en uno de imposibilidad absoluta, que eximirá o no al deudor según concurran las condiciones de la fuerza mayor o caso fortuito. Alemania, Código Civil, Bürgerliches Gesetzbuch, BGB, Boletin del Reich, 24 de agosto de 1896.

10 No asimilamos el caso fortuito a la imposibilidad, en su propia esencia, la primera exonera de responsabilidad porque el cumplimiento no es exigible al deudor y, la segunda, libera al deudor. En el caso en cuestión, al deudor no le es exigible cumplir en atención a la diligencia que le es exigible según el contrato. Para un estudio del caso fortuito y de sus efectos de exoneración, distinguiéndolo de la imposibilidad de cumplimiento (liberatoria), en general: MARÍA GRACIELA BRANTT-ZUMARÁN, El caso fortuito y su incidencia en el derecho de la responsabilidad civil contractual: concepto y función del caso fortuito en el Código Civil chileno (Publicaciones Profesionales, Santiago de Chile, 2010). Chile, Código Civil, Ley de 14 de diciembre de 1855, Diario Oficial, 16 de mayo de 2000.

11 HARRIET SCHELHAAS, Comment to Arts. 7.2.1-7.2.5 (Right to performance), en Commentary on the UNIDROIT Principles of International Commercial Contracts (PICC), 881-915, 895 (STEFAN VOGENAUER, ed., Oxford University Press, Oxford, 2015).

12 Id., 896.

13 ÁLVARO VIDAL-OLIVARES, La pretensión de cumplimiento especifico y su inserción en el sistema de remedios por incumplimiento en el Código Civil, en Estudios de Derecho Civil II, 517-537, 522-528 (HERNÁN CORRAL-TALCIANI \& MARÍA SARA RODRÍGUEZ-PINTO, coords., IV Jornadas Nacionales de Derecho Civil, Olmué, 3-5 de agosto de 2006, LexisNexis, Santiago de Chile, 2007). ÁLVARO VIDAL-OLIVARES, La pretensión de cumplimiento específico de las obligaciones no dinerarias y los costes excesivos para el deudor como limite a su ejercicio, en Estudios de Derecho Civil IX, 555-578, 562-563, 570 (Legal Publishing Thomson Reuters, Valparaíso, 2015). En otra dirección, fundamentando el límite económico, no en la buena fe objetiva, sino en la doctrina del abuso del derecho: CARLOS PIZARRO-WILSON, Notas acerca de..., 203-219, 213 (2014). PATRICIA VERÓNICA LÓPEZ-DÍAZ, El abuso del derecho de opción del acreedor y..., 13-62 (2012). El argumento para preferir el abuso del derecho sobre la buena fe es que esta última constituye un concepto jurídico indeterminado, argumento que se debilita si se tiene en cuenta la falta de acuerdo acerca de los requisitos o exigencias que deben concurrir para concluir que hay abuso del derecho.

14 Entre otros, destacando la función delimitadora de la buena fe: JOSÉ LUIS DE LOS MOZOS, El principio de la buena fe. Sus aplicaciones prácticas en Derecho Civil español (Bosch, Barcelona, 1965). DELIA MATILDE FERREIRA-RUBIO, La buena fe. El principio general en el derecho civil (Montecorvo, Madrid, 1984). FERNANDO FUEYO-LANERI, Instituciones de Derecho Civil moderno (Editorial Jurídica de Chile, Santiago, 1990). ALEJANDRO GUZMÁN-BRITO, La buena fe en el Código Civil 
de Chile, 29 Revista Chilena de Derecho, 1, 11-23 (2002). HERNÁN CORRAL-TALCIANI, La aplicación jurisprudencial de la buena fe objetiva en el ordenamiento civil chileno, 12-13 Revista de Derecho Privado de la Universidad Externado de Colombia, 143-178 (2007). OLE LANDO, Is Good Faith an Over-Arching General Clause in the Principles of European Contract Law?, 15 European Review of Private Law, 6, 841-853 (2007). CRISTIÁN BOETSCH-GILLET, La buena fe contractual (Editorial Jurídica, Santiago, 2011).

15 ÁLVARO VIDAL-OLIVARES, La gestión razonable de los efectos del incumplimiento en la compraventa internacional, XVIII Revista de Derecho de la Universidad Austral de Chile, 2, 55-81 (2005).

16 La solución de los Principios Latinoamericanos de Derecho de los Contratos (PLDC) se reservará para el final, por tratarse de una normativa más cercana a la chilena. Estos principios son fruto de un grupo de profesores de derecho civil latinoamericanos, entre los que se cuenta una importante participación nacional.

17 "This is the case when the repair is unreasonably expensive for the seller". MARKUS MÜLLER-CHEN, Commentary on the Art. 46 CISG, en Commentary on the UN Convention on the International Sales of Goods (CISG), 705-723, 709 (PETER SCHLECHTRIEM \& INGEBORG SCHWENZER, eds., Oxford University Press, Oxford, 2005)

18 Artículo 7.2.2. "Si una parte no cumple una obligación distinta a la de pagar una suma de dinero, la otra parte puede reclamar la prestación, a menos que: (b) la prestación o, en su caso, la ejecución forzosa, sea excesivamente gravosa u onerosa”. La regla atiende exclusiva y aisladamente al coste del incumplimiento, en este caso excesivo o desproporcionado. En el Comentario b) al precepto citado se ofrece un ejemplo: " 1 . Un buque petrolero naufraga en aguas costeras durante una fuerte tempestad. Aunque sería posible recuperar el buque del fondo del mar, el cargador no podría reclamar el cumplimiento del contrato de transporte si esto fuese a ocasionar al naviero gastos muy por encima del valor del petróleo".

19 Reiterando la regla de los UNIDROIT, en los PECL se lee: "(1) The aggrieved party is entitled to specific performance of an obligation other than one to pay money, including the remedying of a defective performance. (2) Specific performance cannot, however, be obtained where: (b) performance would cause the obligor unreasonable effort or expense".

20 Similarmente, en el DCFR: III. 3:302, (3), b). “(3) Specific performance cannot, however, be enforced where: (b) performance would be unreasonably burdensome or expensive”.

21 La ejecución de las obligaciones no dinerarias procederá salvo si su costo es manifiestamente irrazonable.

22 Artículo 1192. "En las obligaciones distintas de las de pagar dinero, el acreedor podrá exigir el cumplimiento de la prestación debida a menos que: $2^{\circ}$ El cumplimiento o, en su caso, las ejecuciones forzosas resulten excesivamente onerosos para el deudor".

23 El cumplimiento no procederá cuando sea contrario a la buena fe o resulte excesivamente oneroso para el deudor (artículo 518-6). Asociación de Profesores de Derecho Civil de España, Propuesta de Código Civil, Libros Quinto y Sexto, 126 (Tirant lo Blanch, Valencia, 2016).

24 Artículo 7.2.2. "Si una parte no cumple una obligación distinta a la de pagar una suma de dinero, la otra parte puede reclamar la prestación, a menos que: (c) La parte legitimada para recibir la prestación pueda razonablemente obtenerla por otra vía”. En el Comentario C del precepto se lee: "Muchos bienes y servicios de tipo estándar son ofertados por diversos proveedores. Si un contrato para tales bienes y servicios de tipo estándar no se cumple, la mayoría de los clientes no estarían dispuestos a perder tiempo y esfuerzos reclamando el cumplimiento específico de la otra parte. Preferirían al mercado a obtener los mismos tipos de bienes o servicios y reclamar el resarcimiento por la falta de cumplimiento"; y se añade que: "La palabra \#razonablemente\# indica que el simple hecho de que el mismo cumplimiento puede ser obtenido de otra fuente no es de por sí suficiente, ya que en ciertas circunstancias la parte perjudicada no podrá recurrir a un proveedor sustituto". Y se proporciona un ejemplo: "A, quien reside en un país en vías de desarrollo, donde el cambio de divisas es muy escaso, compra una máquina de tipo estándar a \#B\#, quien reside en Tokio. En virtud del contrato \#A\# paga antes de la entrega el precio de US\$100.000. \#B\# no cumple con su obligación de entrega. Aunque \#A\# podría obtener en Japón otra máquina de ese mismo tipo, esto no sería razonablemente exigible, debido a la escasez y costo del cambio de divisas en el país de \#A\#. En este supuesto \#A\# tiene derecho a reclamar a \#B\# la entrega de la máquina prometida”.

25 "(1) The aggrieved party is entitled to specific performance of an obligation other than one to pay money, including the remedying of a defective performance. (2) Specific performance cannot, however, be obtained where: (d) the aggrieved party may reasonably obtain performance from another source". (1) La parte perjudicada tiene derecho a reclamar el cumplimiento en forma específica de las obligaciones no pecuniarias y a la reparación del cumplimiento defectuoso de las mismas. (2) Sin embargo, el cumplimiento en forma específica no podrá obtenerse cuando: (d) el perjudicado pueda obtener de manera razonable la prestación por otras vías. 
26 "(5) The creditor cannot recover damages for loss or a stipulated payment for non-performance to the extent that the creditor has increased the loss or the amount of the payment by insisting unreasonably on specific performance in circumstances where the creditor could have made a reasonable substitute transaction without significant effort or expense".

27 Artículo 110. 1. El comprador tendrá derecho a reclamar el cumplimiento de las obligaciones del vendedor. 3. El cumplimiento no podrá reclamarse cuando (b) sea desproporcionadamente gravoso y oneroso respecto del beneficio que obtendría el comprador.

28 Artículo 111: Cuando, en un contrato de compraventa de bienes de consumo se exija al comerciante subsanar una falta de conformidad de acuerdo con el artículo 110, apartado 2, el consumidor podrá optar entre reparación o sustitución, salvo que la opción escogida fuera ilícita o imposible o, comparada con la otra opción disponible, impusiera costes al vendedor que fueran desproporcionados teniendo en cuenta: (a) el valor que tendrían los bienes en caso de que no hubiese falta de conformidad; (b) la importancia de la falta de conformidad; y (c) si se podría completar la subsanación alternativa sin inconveniente importante para el consumidor.

29 Corresponde a la versión final aprobada el Encuentro del Grupo de Trabajo en Bogotá (Colombia), en agosto de 2017. Para un texto, en su versión en español, francés, inglés e italiano, junto a unos comentarios: ÍNIIGO DE LA MAZA-GAZMURI, CARLOS PIZARRO-WILSON \& ÁLVARO VIDAL-OLIVARES, Los principios latinoamericanos de derecho de los contratos, una primera aproximación (Colección Derecho Privado, BOE, Boletín Oficial del Estado, Madrid, 2017).

30 Distinguiendo y explicando la diferencia entre la desproporción absoluta y relativa en los artículos 110 y 111 del CESL: FRYDERYK ZOLL, European Contract Law, en Common European Sales Law (CESL), A Commentary, 506-510 (REINER SCHULZE, ed., Beck, Hart, Nomos, Oxford, 2012).

31 Aunque el artículo 518-6, letra b) de la Propuesta de Código Civil español introduce el límite de la buena fe —sin precisar su alcance-, como distinto a la excesiva onerosidad del cumplimiento para el deudor.

32 ÁLVARO VIDAL-OLIVARES, La gestión razonable... (2005).

33 La redacción de la norma del artículo 1193.II.2 de la Propuesta española que define como límite "la excesiva onerosidad del cumplimiento" y la del artículo 1213 de la misma propuesta que prevé el cambio extraordinario e imprevisible de las circunstancias que sirvieron de base al contrato, exigen grandes esfuerzos para delinear el ámbito de aplicación de cada disposición, a objeto de evitar la confusión entre el límite económico a la pretensión de cumplimiento específico y la imprevisión por excesiva onerosidad. Así se desprende de la obra de NIEVES FENOY-PICÓN. Esta jurista expresa: "En conclusión, puede interpretarse: a) Si el cumplimiento es excesivamente oneroso para el deudor en relación con el interés que aquel proporciona al acreedor, procede aplicar el artículo 1192. II. 2 PC, b) Si el cumplimiento es oneroso debido a una alteración extraordinaria de las circunstancias básicas del contrato, procede aplicar el artículo 1213 PC". NIEVES FENOY-PICÓN, La modernización del régimen del incumplimiento del contrato: propuestas de la Comisión General de Codificación. Parte segunda: los remedios por incumplimiento, LXIV Anuario de Derecho Civil, ADC, 4, 1481-1685, 1517-1523 (2011).

34 Chile, Corte Suprema, 09 de septiembre de 2009, South Andes Capital S.A. con Empresa Portuaria de Valparaíso, Rol 2651-08. Para un contrapunto en esta materia, es posible consultar, por una parte, las opiniones de CLAUDIO ILLANES \&, JUAN CARLOS DÖRR, Estudios sobre Reformas al Código Civil y al Código de Comercio, 221-242 (Editorial Jurídica de Chile, Santiago de Chile, 2000). Por la conveniencia de su reconocimiento legal y un análisis de la jurisprudencia judicial, arbitral y administrativa, RODRIGO MOMBERG-URIBE, Teoria de la imprevisión: la necesidad de su regulación legal en Chile, 15 Revista Chilena de Derecho Privado, RChDP, 29-64 (2010).

35 RODRIGO MOMBERG-URIBE, Análisis crítico desde el derecho alemán y nacional de la sentencia de la Corte de Apelaciones de Santiago que acoge la teoria de la imprevisión, en Estudios de Derecho Civil III, 637-658 (ALEJANDRO GUZMÁN-BRITO, ed., Legal Publishing, Santiago, 2008).

36 Referencias a la jurisprudencia arbitral en RODRIGO MOMBERG-URIBE, Teoria de la imprevisión..., 29-64 (2010).

37 Art. 6.2.1 (Obligatoriedad del contrato): Cuando el cumplimiento de un contrato llega a ser más oneroso para una de las partes, esa parte permanece obligada, no obstante, a cumplir sus obligaciones salvo lo previsto en las siguientes disposiciones sobre "excesiva onerosidad" ( hardship). Art. 6.2.2 (Definición de la "excesiva onerosidad" (hardship)): Hay "excesiva onerosidad" ( $h a r d s h i p$ ) cuando el equilibrio del contrato es alterado de modo fundamental por el acontecimiento de ciertos eventos, bien porque el costo de la prestación a cargo de una de las partes se ha incrementado, o porque el valor de la prestación que una parte recibe ha disminuido, y: (a) dichos eventos acontecen o llegan a ser conocidos por la parte en desventaja después de la celebración del contrato; (b) los eventos no pudieron ser razonablemente tenidos en cuenta por la parte en desventaja en el momento de celebrarse 
el contrato; (c) los eventos escapan al control de la parte en desventaja; y (d) el riesgo de tales eventos no fue asumido por la parte en desventaja. Art. 6.2.3 (Hardship) Efectos de la "excesiva onerosidad" (hardship): (1) En caso de "excesiva onerosidad" (hardship), la parte en desventaja puede reclamar la renegociación del contrato. Tal reclamo deberá formularse sin demora injustificada, con indicación de los fundamentos en los que se basa. (2) El reclamo de renegociación no autoriza por sí mismo a la parte en desventaja para suspender el cumplimiento. (3) En caso de no llegarse a un acuerdo dentro de un tiempo prudencial, cualquiera de las partes puede acudir a un tribunal. (4) Si el tribunal determina que se presenta una situación de "excesiva onerosidad" (hardship), y siempre que lo considere razonable, podrá: (a) resolver el contrato en fecha y condiciones a ser fijadas; o (b) adaptar el contrato con miras a restablecer su equilibrio.

38 Art. 6:111: Cambio de circunstancias. (1) Las partes deben cumplir con sus obligaciones, aun cuando les resulten más onerosas como consecuencia de un aumento en los costes de la ejecución o por una disminución del valor de la contraprestación que se recibe. (2) Sin embargo, las partes tienen la obligación de negociar una adaptación de dicho contrato o de poner fin al mismo si el cumplimiento del contrato resulta excesivamente gravoso debido a un cambio de las circunstancias, siempre que: (a) Dicho cambio de circunstancias haya sobrevenido en un momento posterior a la conclusión del contrato. (b) En términos razonables, en el momento de la conclusión del contrato no hubiera podido preverse ni tenerse en consideración el cambio acaecido. (c) A la parte afectada, en virtud del contrato, no se le pueda exigir que cargue con el riesgo de un cambio tal de circunstancias. (3) Si en un plazo razonable las partes no alcanzan un acuerdo al respecto, el juez o tribunal podrá: (a) Poner fin al contrato en los términos y fecha que considere adecuado. (b) $\mathrm{O}$ adaptarlo, de manera que las pérdidas y ganancias resultantes de ese cambio de circunstancias se distribuyan entre las partes de forma equitativa y justa. En cualquiera de los casos, el juez o tribunal podrá ordenar que la parte que se negó a negociar o que rompió dicha negociación de mala fe, proceda a reparar los daños causados a la parte que sufrió dicha negativa o dicha ruptura.

39 III. - 1:110: Variation or termination by court on a change of circumstances. (1) An obligation must be performed even if performance has become more onerous, whether because the cost of performance has increased or because the value of what is to be received in return has diminished. (2) If, however, performance of a contractual obligation or of an obligation arising from a unilateral juridical act becomes so onerous because of an exceptional change of circumstances that it would be manifestly unjust to hold the debtor to the obligation a court may: (a) vary the obligation in order to make it reasonable and equitable in the new circumstances; or (b) terminate the obligation at a date and on terms to be determined by the court. (3) Paragraph (2) applies only if: (a) the change of circumstances occurred after the time when the obligation was incurred; (b) the debtor did not at that time take into account, and could not reasonably be expected to have taken into account, the possibility or scale of that change of circumstances; (c) the debtor did not assume, and cannot reasonably be regarded as having assumed, the risk of that change of circumstances; and (d) the debtor has attempted, reasonably and in good faith, to achieve by negotiation a reasonable and equitable adjustment of the terms regulating the obligation.

40 Artículo 89 Cambio en las circunstancias

1. Una parte deberá cumplir sus obligaciones aun cuando el cumplimiento de las mismas resulte más oneroso como consecuencia de un aumento en los costes de la ejecución o por una disminución del valor de la contraprestación que se recibe.

Cuando el cumplimiento resulte excesivamente oneroso debido a un cambio excepcional en las circunstancias, las partes tendrán el deber de iniciar negociaciones para adaptar o resolver el contrato.

2. Si las partes no llegan a un acuerdo en un plazo razonable, un órgano jurisdiccional, a petición de cualquiera de las partes, podrá: (a) adaptar el contrato para adecuarlo a lo que las partes habrían razonablemente acordado en el momento de su celebración si hubieran tenido en cuenta el cambio en las circunstancias; o

(b) resolver el contrato a tenor del artículo 8 en fecha y condiciones que deberán ser fijadas por él.

3. Los apartados 1 y 2 se aplicarán únicamente si: (a) el cambio en las circunstancias se produjo después de la celebración del contrato;

a) la parte que invoca el cambio de circunstancias no tuvo en cuenta en ese momento, y no pueda esperarse que lo tuviese en cuenta, la posibilidad de que se produjese dicho cambio en las circunstancias o la magnitud del mismo; y

b) la parte perjudicada no asumió, y es razonable suponer que no asumiera, el riesgo de dicho cambio en las circunstancias. 
1. Si, después de su celebración, la ejecución del contrato deviene excesivamente onerosa o su utilidad disminuye significativamente, por cambio de circunstancias cuyo acaecimiento o magnitud no pudo razonablemente haberse previsto y cuyo riesgo no fue asumido por la parte afectada, esta puede solicitar a la otra la renegociación del contrato.

2. La renegociación no suspende la ejecución del contrato, salvo cuando esta cause perjuicios irreparables para la parte afectada.

3. Si después de un plazo razonable las mismas partes no han adaptado el contrato, cualquiera de ellas puede solicitar al juez que lo adapte o resuelva, quien para hacerlo debe tener en cuenta la distribución de riesgos y costos que habían asumido las partes.

42 Art. 1195.-Si un changement de circonstances imprévisible lors de la conclusion du contrat rend l'exécution excessivement onéreuse pour une partie qui n'avait pas accepté d'en assumer le risque, celle-ci peut demander une renégociation du contrat à son cocontractant. Elle continue à exécuter ses obligations durant la renégociation. En cas de refus ou d'échec de la renégociation, les parties peuvent convenir de la résolution du contrat, à la date et aux conditions qu'elles déterminent, ou demander d'un commun accord au juge de procéder à son adaptation. A défaut d'accord dans un délai raisonnable, le juge peut, à la demande d'une partie, réviser le contrat ou y mettre fin, à la date et aux conditions qu'il fixe.

43 Así, por ejemplo, ABELIUK-MANASEVICH la define como "la facultad del deudor de solicitar la resolución o revisión del contrato de ejecución postergada cuando un imprevisto ajeno a la voluntad de las partes ha transformado su obligación en exageradamente onerosa”. RENÉ ABELIUK-MANASEVICH, Las obligaciones, 756 (4a ed. actualizada, Editorial Jurídica de Chile, Santiago, 2003). En el mismo sentido, JUAN CARLOS DÖRR, Notas acerca de la teoría de la imprevisión, V Revista Chilena de Derecho, 12, 253-270 (1985).

44 Respecto al concepto de imprevisión, RODRIGO MOMBERG-URIBE, Teoría de la imprevisión..., 29-64 (2010).

45 Sobre el ejercicio de los remedios contractuales conforme a la buena fe: ÁLVARO VIDAL-OLIVARES, La carga de mitigar las pérdidas del acreedor y su incidencia en el sistema de remedios por incumplimiento, en Estudios de Derecho Civil III, Jornadas Nacionales de Derecho Civil, Valparaíso, 2007, 429-457 (ALEJANDRO GUZMÁN-BRITO, ed., Legal Publishing, Santiago, 2008). Acerca del límite al cumplimiento específico, aunque desde la doctrina del abuso del derecho, aunque fundada en la buena fe objetiva: CARLOS PIZARRO-WILSON, Notas acerca de los limites a la pretensión de cumplimiento del contrato, 21 Revista de Derecho, Universidad Católica del Norte, RDUCN, 1, 203-219, 210-213 (2014).

46 Un análisis del sistema de remedios, puede verse en RODRIGO MOMBERG-URIBE, El sistema de remedios para el caso de imprevisión o cambio de circunstancias, en Cuadernos de análisis juridico. Colección de Derecho Privado VII, Incumplimiento contractual: nuevas perspectivas, 83-105 (ÍNIGO DE LA MAZA-GAZMURI, coord., Ediciones Universidad Diego Portales, Santiago de Chile, 2011).

47 Para un examen del deber de renegociación, RODRIGO MOMBERG-URIBE, La revisión del contrato por las partes: el deber de renegociación como efecto de la excesiva onerosidad sobreviniente, 37 Revista Chilena de Derecho, 1, 43-72 (2010).

48 Debe tenerse presente que el objeto del sistema de remedios en caso de imprevisión debe ser el de distribuir el mayor costo originado por el cambio de circunstancias hasta hacerlas soportables, de acuerdo a la economía del contrato, para la parte afectada. En otras palabras, la modificación no debe implicar que se restaure completamente el equilibrio inicial del contrato, trasladando las consecuencias del cambio de circunstancias de una parte hacia la otra. De esta manera, el interés del acreedor no queda completamente desplazado, ya que hasta el punto en que la prestación se ha transformado en excesivamente onerosa, el deudor debe soportar el riesgo de que los costos de su prestación hayan aumentado o de que el valor de la contraprestación que recibe haya disminuido. Al efecto, CHRISTOPH BRUNNER, Force Majeure and Hardship under General Contract Principles, 499 (Kluwer Law International, The Hague, 2008). También RODOLFO SACCO \& GIORGIO DE NOVA, Il contratto, 1003 (Unione Tipografico-Editrice Torinese, UTET, Torino, 2004).

49 Las normas de derecho uniforme establecen claramente que, para el caso de imprevisión, el juez debe tener amplias facultades para determinar los términos de la extinción anticipada del contrato, en cuanto a su fecha, restituciones y retenciones, indemnizaciones, destino de las obligaciones pendientes o parcialmente ejecutadas, etc. Se busca evitar que parte de los riesgos se trasladen injustificadamente al acreedor o se produzcan perjuicios a terceros, como podría suceder con contratos de larga duración que provean bienes de utilidad pública, donde una interrupción del servicio podría producir efectos negativos a la comunidad. 
Rodrigo Momberg-Uribe, et al. El límite económico al cumplimiento de contrato. Desde la excesiva ...

Para citar este articulo/To cite this article: MOMBERG-URIBE, RODRIGO \& VIDAL-OLIVARES, ÁLVARO, El limite económico al cumplimiento de contrato. Desde la excesiva onerosidad sobrevenida a los excesivos del cumplimiento especifico, 137 Universitas, $\mathrm{xxx}-\mathrm{xxx}$ (2018). https://doi.org/10.11144/ Javeriana.vj137.lecc 